\title{
EL ROMANCERO EN AMÉRICA Y LA TRADICIÓN CUBANA
}

\author{
AURELIO GONZÁLEZ
}

1

Ramón Menéndez Pidal, Romancero hispánico, $2^{a}$ ed., EspasaCalpe, Madrid, 1968, p. 226.

2

Véase Alejo Carpentier, La música en Cuba, Fondo de Cultura Económica, México, 1972, pp. 21-22. [19 ed. 1946]

\section{3}

Bernal Díaz del Castillo, Historia verdadera de la conquista de la Nueva España, ed. de Carmelo Sáenz de Santa María, Patria, México, 1983, capítulo 36.
El romancero en América y la tradición cubana

AURELIO GONZÁLEZ

\section{NOTICIA Y RECOLECCIÓN DEL ROMANCERO EN AMÉRICA}

Menéndez Pidal considera que «podemos decir con seguridad que un copioso romancero pasó a América en la memoria de aquellos que tripulaban las naves descubridoras y en el recuerdo de cuantos después allá fueron»1. El género romancístico acompaña a los navegantes, misioneros, exploradores, soldados y funcionarios al Nuevo Mundo como parte de su bagaje cultural tradicional pues los versos de los romances reflejan los valores de su comunidad, además de contener historias fascinantes y ejemplos de vida desde el mundo de la ficción. Además, los hombres y mujeres que los cantan lo hacen de manera natural, con la tranquilidad del saber no aprendido.

En su primer viaje Colón desembarcó en Cuba en 1492, esperando encontrar el palacio del Gran Khan; no lo halló, pero en poco tiempo, la isla fue el punto de pasaje obligado para el avance al nuevo mundo; la colonización de la isla comenzó realmente en 1512, cuando el capitán español Diego Velázquez de Cuéllar fundó la ciudad de Baracoa en la costa oriental de la isla. Posteriormente fundaría otros asentamientos importantes, como Bayamo, Santiago de Cuba en 1514 y La Habana en 1515 que convirtieron a Cuba en la base de abastecimiento para las expediciones a México y la Florida. En esas ciudades es seguro que se oirían cantar los romances en las faenas de trabajo o en las reuniones de soldados y aventureros en las cuales se recordarían las hazañas que contaban los ciclos épicos y caballerescos de estas baladas que son los romances.

Porras, cantor, Alonso Morón, vihuelista, y Ortiz, el músico, soldados que formaron parte de la expedición de Cortés a México, primero se asentaron en Cuba, concretamente en Bayamo y Trinidad, y es natural, por la importancia y valoración que tenía en esa época el género, que entre los textos que formaban su repertorio se hayan contado los romances, tanto aquellos famosos que estaban en boga como algunos otros tal vez oídos en su niñez. Este repertorio seguramente lo cantaron durante su estancia en Cuba pues ahí se dedicaron a la actividad musical ${ }^{2}$.

Al hablar del Romancero en América es un lugar común mencionar el diálogo entre Hernán Cortés y Alonso Hernández Puertocarrero - salidos de Cuba en 1518 - frente a la isla de San Juan de Ulúa, en las costas de la que llamarían Nueva España, en el cual ambos emplean versos de romance, uno con los de Montesinos que se inicia

Cata Francia, Montesinos, cata París, la ciudad, cata las aguas de Duero, do van a dar en la mar;

y la respuesta con los del romance de Gaiferos:

denos Dios ventura en armas como al paladín Roldán;

diálogo que relata vivamente en su crónica Bernal Díaz del Castillo 3 . El episodio retrata perfectamente la forma en que el Romancero estaba arraigado en la expresión coloquial de los hombres del siglo XVI ya que en ese momento la cultura tradicional está plenamente vigente y posee una dinámica que le permite acompañar al hombre en todas sus actividades, no sólo en el momento de la reunión o la fiesta o el trabajo, y ello es válido aun en el nuevo ámbito apenas conocido de esa tierra sorpren- 
dente y maravillosa que es América. Esta consideración sigue siendo válida aunque el diálogo no se haya llevado a cabo en esa forma y pueda ser simplemente un recurso literario de Bernal, en cuyo caso implicaría que él efectivamente conocía los romances sin ser un hombre de letras y que para sus receptores era absolutamente verosímil un diálogo de ese tipo.

También se cuenta en esta crónica de la conquista de Nueva España que cuando Cortés llora en Tacuba la muerte de algunos de sus hombres, el bachiller Alonso Pérez al tratar de consolarlo hace referencia al romance que empieza:

\section{Mira Nero de Tarpeya \\ a Roma cómo se ardía ;}

Los testimonios sobre la presencia de Romancero en el continente recién descubierto se remontan al mencionado de 1519 y son frecuentes a lo largo de todo el siglo. Otros cronistas, además de Bernal Díaz del Castillo, como Fernández de Oviedo (en su Historia general de las Indias nos dice a propósito del naufrago Alonso Zuazo en 1524: «Buenas las traemos, señor, pues que venimos acá»), Pedro Cieza de León (a propósito del complot de Gonzalo Pizarro contra Almagro en 1537: «Tiempo es, el caballero, tiempo es de andar de aquí») y Diego Fernández Palencia (con motivo de la derrota que infligió el rebelde Hernández Girón a las tropas reales en la batalla de Chuquinga, Perú, en 1554: «no van a pie los romeros, que en buenos caballos van»). Todos ellos nos proporcionan testimonios de la presencia del Romancero en América en los primeros tiempos del descubrimiento y la Conquista en el lenguaje coloquial. Desde luego esto no excluye la vida del romance en sí mismo como historias que se escuchan con placer, como cuenta Pedro Gutiérrez de Santa Clara que hizo Francisco de Carvajal en 1547 cuando, hallándose enfermo, pidió que le cantaran «el romance de Gaiferos o las coplas del Marqués de Mantua»5.

Por otra parte, la llegada de cancionerillos, pliegos sueltos y romanceros también está documentada ${ }^{6}$ ya a lo largo de todo el siglo XVI. La difusión del Romancero por medio de la imprenta, al proporcionar un soporte escrito permanente, dinamiza las innovaciones y funciona como un refuerzo de los textos tradicionales y juglarescos viejos.
En América se afincará ese transmisor - en realidad no importa mucho que sea un clérigo misionero, un bachiller letrado, un soldado o un simple hidalgo o villano en busca de fortuna- que es poseedor de una cultura tradicional y un espíritu juglaresco que le permite refuncionalizar y adaptar las historias de los romances a su nuevo contexto social e ideológico, lo mismo que transformar las acciones y los hechos cotidianos de la Conquista en materia literaria, tal como sucedía en España ${ }^{7}$. No se trata ahora de refundiciones sino de creaciones y recreaciones que pueden darse en un ámbito culto, pero también correr el abierto espacio de la tradición oral, como por ejemplo:

En Tacuba está Cortés con su escuadrón esforzado; triste estaba y muy penoso, triste y con muy gran cuidado, la una mano en la mejilla y la otra en el costado.

En otros casos tal vez pueda tratarse de romances al modo culto, con un espíritu más bien cronístico o erudito, lo cual explicaría en algunos momentos la falta de vuelo poético tanto culto como incluso tradicional. El Romancero se afinca en el Nuevo Mundo y así es que encontramos huellas de la presencia del Romancero tradicional y también del artificioso Romancero nuevo tan en boga en la época gracias al impulso de Lope, Góngora o Liñán de Riaza, en autores cultos novohispanos como Fernán González de Eslava quien en el último cuarto del siglo XVI (muere hacia 1603) cita o contrahace hasta treinta romances nuevos y viejos en sus Coloquios espirituales y sacramentales, destacando la «Ensalada de San Miguel» ${ }^{8}$ en la que, entre otros, utiliza versos de El prisionero, El infante vengador, Virgilios, Roncesvalles, etc., los cuales necesariamente debían de ser del dominio común pues de lo contrario no se justificaría su utilización en una ensalada alegre ante un público multirracial y popular?

Por otra parte, así como el hombre europeo se acomodó a las condiciones climáticas y nuevas estructuras sociales que le planteaba el nuevo continente y dio lugar a una descendencia americana, también el Romancero se integró a la cultura americana, modificando muchos de sus aspectos y generando manifestaciones innovadoras propias de la nueva cultura.

En este transplante a tierras americanas, merced a la apertura propia del género, el romance se enriquece con términos nuevos, secuencias narrativas, formas particulares, etc.,
4 Bernal Díaz de Castillo, op. cit., cap. 145

5

Véase Emilia Romero, El romance tradicional en el Perú, El Colegio de México, México, 1952, pp. 14-16.

6

Véase Irving Leonard, Los libros del conquistador, Fondo de Cultura Económica, México, 1953, pp. 110-111. Por ejemplo, en el pagaré de 1576 de Alfonso Losa, mercader de libros, de la Ciudad de México, constan "unos Romances viejos, papelones a 4 reales», p. 286.

7

Sobre el Romancero y el tema de la Conquista puede verse mi artículo: Aurelio González, «Los romances de la Conquista: enfoques y perspectivas", en Relaciones literarias entre América y España en los siglos XVI y XVII, Universidad Autónoma de Ciudad Juárez, México, 1992, pp. 211-224.

8

Fernán González de Eslava, Villancicos, romances, ensaladas y otras canciones devoras, ed. de Margit Frenk, El Colegio de México, México, 1989, pp. 229 232.

9

Cf. Margit Frenk, «Romances y villancicos en la Nueva España del siglo XVI (El testimonio de González de Eslava), en E. Rodríguez Cepeda (ed.), Actas del Congreso Romancero Cancionero UCLA (1984), Porrúa Turanzas, Madrid, 1990, t. II, p. 332.

El romancero en América y la tradición cubana

AURELIO GONZÁLEZ 
10

Véase en el número monográfico sobre Literatura popular. Conceptos, argumentos, temas coordinado por María Cruz García de Enterría, mi artículo «La tradición del Romancero en Américal, Anthropos, 166-167 (1995), pp. 145-147.

11

Manuel da Costa Fontes, Romanceiro Português do Canadá, Universidade Coimbra, Coimbra, 1979.

12

Véase Ramón Menéndez Pidal, "Las primeras noticias de romances tradicionales en América y especialmente en Colombia", Homenaje a Enrique José Varona, Dirección de Cultura de la Secretaría de Educación, La Habana, 1935, pp. 23-27. Publicado originalmente en la Revista Cubana, I-1 (1935), pp. 12-13.

13

"La poesía popular en la América del Sur», Revista de Archivos Bibliotecas y Museos, 6 (1902), pp. 43-49.

\section{4}

«Los romances tradicionales de América», Cultura Española, 1906, pp. 72-111. Reeditada en forma definitiva en Los romances de América y otros estudios, Espasa-Calpe, Madrid, 1939, (Austral, 55).

\section{5}

Julio Vicuña Cifuentes, Romances populares y vulgares recogidos de la tradición oral chilena, Imprenta Barcelona, Santiago de Chile, 1912

\section{6}

Raquel Barros y Manuel Dannemann, El Romancero chileno, Universidad de Chile, Santiago, 1970.

El romancero en América y la tradición cubana

AURELIO GONZÁLEZ al tiempo que permite que en algunos casos el texto deje de ser un romance y se convierta, por ejemplo, en un corrido, nuevo género americano, hijo del romance tradicional oral y del romance vulgar de pliego y nieto de la balada europea, que en México desplaza en vitalidad al propio romance.

Después del periodo colonial nos encontramos con otros fenómenos y así hay que entender también que en la América independiente, después del período de la ruptura con España, hay un momento posterior en que se percibe que el verdadero peligro es la aculturación proveniente del ámbito estadounidense y se trata de rescatar una forma de tradición de tipo hispánico. En este sentido el Romanticismo había traído consigo el redescubrimiento de la tradición romancística española de origen medieval, misma que, por ejemplo en México, Argentina y otros países de América también fue conocida por los autores liberales y conservadores a través de los románticos españoles.

En general, en muchas de las obras de estos autores a lo largo y ancho del continente americano aparecen presencias, a través de temas, formas, motivos, etc. de la literatura tradicional, podríamos decir que, por una motivación de tipo ideológico relacionada con la creación de una cultura nacional, en ese momento del siglo XIX coexisten las dos formas culturales, pero es evidente la distancia que tenían con respecto a un auténtico conocimiento de la literatura del pueblo.

Hoy en día los testimonios de la presencia del Romancero en América abarcan desde la pampa argentina hasta las pequeñas poblaciones de las zonas desérticas del sur de Estados Unidos y las poblaciones costeras de Terranova en Canadá; su presencia se detecta en las pequeñas poblaciones serranas y en núcleos urbanos de relativa importancia de México, Perú, Colombia, Venezuela o Brasil, se le encuentra en la tierra firme y en las islas de Cuba, Puerto Rico o la Dominicana y es más vital en las poblaciones del interior que en las costas, que parecen preferir la canción lírica, tal como sucede en la tradición peninsular ibérica ${ }^{10}$.

Independientemente del flujo de emigrantes españoles y portugueses a lo largo de quinientos años, la tradición americana se ha enriquecido en las últimas décadas con la emigración portuguesa, en especial de las Azores, al Canadá y a los Estados Unidos (tradición recogida primero por Joanne Purcell,
1968, y después por Manuel da Costa Fontes ${ }^{11}$, 1979, 1980 y 1983 en ambos países) y el desplazamiento de sefarditas orientales o del Norte de África, a raíz de la II Guerra Mundial, a estos mismos países (Canadá: Oro AnahoryLibrowicz, 1988, Estados Unidos: Samuel G. Armistead y Joseph Silverman) y a algunos de habla española como la Argentina, y desde luego la emigración española por motivos económicos de las dos primeras décadas del siglo de asturianos y gallegos a Cuba, México y la Argentina, el exilio republicano a raíz de la Guerra Civil en 1939 y los primeros años 40, así como de emigrantes canarios a Venezuela en la última migración en los años sesenta.

Se calcula que el corpus romancístico de la tradición oral moderna americana que se ha recogido está integrado por más de 2.200 versiones de unos cincuenta romances. En el descubrimiento en América de la tradición oral moderna romancística tuvo mucho que ver, como en tantas otras cosas relacionadas con el Romancero, Ramón Menéndez Pidal, en esta ocasión con su viaje a América en 1905 como comisario especial para llevar a cabo los trabajos preparatorios del laudo que había de emitir el rey de España sobre los límites en conflicto entre Perú y Ecuador. Por otra parte la primera noticia moderna sobre el Romancero en América la proporciona el filólogo colombiano Rufino José Cuervo en 1874, en el Anuario de la Academia Colombiana, donde menciona haber oído cantar a "un inculto campesino... en un desconocido valle de los Andes» ${ }^{12}$ romances de Bernardo del Carpio y de los siete infantes de Lara, aunque sin proporcionar ningún texto. Las primeras versiones de la tradición oral moderna americana fueron dadas a conocer en 1902 por Ciro Bayo en la Revista de Archivos, Bibliotecas y Museos $^{13}$, se trata de versiones recogidas en Argentina (o en Bolivia) de Las señas del esposo y del Conde Olinos. Mismas que más tarde (1905) publicaría en Quito Menéndez Pidal en un pliego suelto y el propio Bayo en su Romancerillo del Plata (Victoriano Suárez, Madrid, 1913).

Posterior a la recolección de Menéndez Pidal de $1905^{14}$ destaca la muestra de Chile publicada por Julio Vicuña Cifuentes ${ }^{15}$ (1912) que incluye romances tradicionales y vulgares. En 1970, Raquel Barros y Manuel Dannemann ${ }^{16}$, darán a conocer una nueva colección de versiones chilenas. Para Argentina, después del trabajo de Bayo destaca la obra de 
Juan Alfonso Carrizo ${ }^{17}$ realizada en la región del Tucumán (provincias de Jujuy, Salta, La Rioja y Catamarca) entre 1926 y 1942 recogiendo romances, coplas, décimas, glosas y todo tipo de estrofas. Posteriormente han recogido romances Juan Draghi (1938), Ismael Moya (1941) a través de las encuestas del magisterio, Isabel Aretz-Thiele (1946) y más recientemente (1996) Gloria Chicote ${ }^{18}$. En los Estados Unidos la tradición romancística está presente en los Estados del sur donde la presencia española y mexicana fue más intensa donde la han recogido Aurelio M. Espinosa (1925-1953) en California ${ }^{19}$ y Nuevo Méxi$\mathrm{co}^{20}$, Arthur L. Campa ${ }^{21}$ (1946) en Nuevo México, Américo Paredes ${ }^{22}$ (1953) en Tejas y Samuel G. Armistead ${ }^{23}$ (1978-1983) en Luisiana. También se han hecho recolecciones entre las comunidades sefardíes de Nueva York y Seattle. La primera recolección en México se debe a Pedro Henríquez Ureña y Bertram Wolfe (1925), posteriormente Vicente T. Mendoza hace su magno trabajo de relación entre el corrido y el romance ${ }^{24}$ (1939), y en 1986 Mercedes Díaz Roig y Aurelio González ${ }^{25}$ editan la suma total de lo publicado así como el resultado de su trabajo de campo. En Puerto Rico trabajó María Cadilla ${ }^{26}$ (1940); en Venezuela: R. Olivares Figueroa (1944-1948), Ramón e Isabel Aretz (1961) y Pilar Almoina ${ }^{27}$ (1975); República Dominicana: Henríquez Ureña ${ }^{28}$ (1913), Edna Garrido ${ }^{29}$ (1946); Uruguay: Marina López Blanquet (1946), Ildefonso Pereda ${ }^{30}$ (1947); Nicaragua: Ernesto Mejía Sánchez $^{31}$ (1946); Perú: Emilia Romero (1952); Guatemala: Carlos Navarrete ${ }^{32}$ (1963); Colombia: Gisela Beutler'33 (1969); Brasil: Rossini Tavares de Lima (1971), Jackson Da Silva Lima (1971), Braulio do Nascimento (1974), José Aloisio Vilela (1983); Costa Rica: Michele Cruz Sáenz ${ }^{34}$ (1986). La recolección en Cuba la encabeza Carolina Poncet (1914) y José María Chacón (1914-1922), en los últimos años se recogieron materiales debido a iniciativas oficiales y de algunos investigadores como Feijoo; recientemente Beatriz Mariscal ${ }^{35}$ ha publicado en México una recopilación de lo editado y de fondos archivísticos. Una valiosa visión global de la tradición romancística americana, recogida a lo largo de casi setenta años, se puede conocer a través de la antología que preparó Mercedes Díaz Roig y publicada póstumamente (1990) ${ }^{36}$. No hay publicaciones de Honduras, Paraguay ${ }^{37}$ y Bo-

livia (en este último país la duda estaría en una de las versiones de Ciro Bayo, primero ubicada en Bolivia y después en Argentina).

\section{EL CORPUS DEL ROMANCERO EN AMÉRICA}

Los principales temas del corpus del Romancero recogido en América son los siguientes $^{38}$ :

Novelescos (la estructura familiar)

Adulterio: La adúltera, Bernal Francés, $L a$ malcasada.

Relaciones prematrimoniales: La bastarda $y$ del segador, Gerineldo, La mala yerba, El caballero herido, *Polonia, La dama y el pastor.

Habilidad de la mujer: La doncella guerrera, Rico Franco, Blancaflor y Filomena, *La condesita, *El caballero burlado.

17

Juan Alfonso Carrizo, Cancionero popular de Salta Baiocco, Buenos Aires, 1933; Cancionero popular de Jujuy, Universidad, Nacional de Tucumán, Tucumán, 1934; Cancionero popular de Tucumán, 2 vols., Espasa-Calpe, Buenos Aires, 1937 y Cancionero popular de La Rioja, 3 vols., Espasa Calpe, Buenos Aires, 1942.

18

Gloria Chicote y Miguel A. García, Romances. Poesía oral de la Provincia de Buenos Aires, Universidad Nacional de La Plata, Buenos Aires, 1996.

\section{9}

Aurelio M. Espinosa, «Romances tradicionales en California», en Homenaje a Menéndez Pidal, Hernando, Madrid, 1925, t. I, pp. 299-313.

20

Aurelio M. Espinosa, Romancero de Nuevo Méjico, Consejo Superior de Investigaciones Científicas, Madrid, 1953, (Anejos de la Revista de Filología Española, 58).

21

Arthur L. Campa, Spanish Folkpoetry in New Mexico, The University of New Mexico Press, Albuquerque, 1946.
22

Américo Paredes, A Texas-Mexican Cancionero, Folksongs of the Lower Border, University of Illinois Press, Urbana, 1976.

23

Samuel G. Armistead, «Romances tradicionales entre los hispanoahablantes del Estado de Luisiana», Nueva Revista de Filología Hispánica, 27 (1978), pp. 39-56 y «Más romances de Luisiana», Nueva Revista de Filología Hispánica, 32 (1983), pp. 41-54.

\section{4}

Vicente T. Mendoza, Romance español y corrido mexicano, Universidad Nacional Autónoma de México, México, 1939.

\section{5}

Mercedes Díaz Roig y Aurelio González, Romancero tradicional de México, Universidad Nacional Autónoma de México, México, 1986.

\section{6}

María, Cadilla, Juegos y canciones infantiles de Puerto Rico, Baldrich, San Juan, 1940.

\section{7}

Pilar Almoina de Carrera, Diez Romances hispánicos de la tradición oral venezolana, Universidad Central de Venezuela, Caracas, 1975.
28

Pedro Henríquez Ureña, «Romances en América", Cuba Contemporánea, 3 (1913), pp. 347366.

29

Edna, Garrido de Boggs, Versiones dominicanas de romances españoles, Pol Hnos., Santo Domingo, 1946.

30

Ildefonso Pereda Valdés, Cancionero popular uruguayo, Floresa y Lafón, Montevideo, 1947.

31

Ernesto Mejía Sánchez, Romances y corridos nicaragüenses, Imprenta Universitaria, México, 1946.

32

Carlos Navarrete, «El romance tradicional y el corrido en Guatemala», Universidad de San Carlos, 59 (1963), 181-254.

\section{3}

Gisela Beutler, Estudios sobre el Romancero español en Colombia, Instituto Caro y Cuervo, Bogotá, 1977.

34

Michele Cruz Sáenz, Romancero tradicional de Costa Rica, Juan de la Cuesta, Newark, 1986.

35

Beatriz Mariscal, Romancero general de Cuba, El Colegio de México, México, 1996.

36

Mercedes Díaz Roig, Romancero tradicional de América, El Colegio de México, México, 1990.

37

En 1982 Germán Granda publica fragmentos de Gerineldo y Alfonso XIl en «El Romancero tradicional español en Paraguay. Razón de una (aparente) anomalia», Thesaurus, Boletín del Instituto Caro y Cuervo, 37 (1982), pp. 118-146.

38

El asterisco (") antes del título indica que el tema generalmente no se encuentra aưónomo y el punto (•) que sólo se han encontrado pervivencias fragmentarias.

El romancero en América y la tradición cubana

AURELIO GONZÁLEZ 
El acervo infantil puede incluir otros textos que hemos clasificado temáticamente como Delgadina, Santa Catalina o Alfonso XII.

\section{0}

M. Díaz Roig, Romancero tradicional de América, op. cit. p. 322.

41

Merle E. Simmons, A Bibliography of the «Romance» and Related Forms in Spanish America, Indiana University Press, Bloomington, 1963.

42

Ana Valenciano, «El Romancero tradicional en la América de habla hispana», Anales de Literaiura Hispanoamericana, 21 (1992), pp. 146-163.
El romancero en América y la tradición cubana

AURELIO GONZÁLEZ
Prueba de fidelidad: ¿Cómo no cantáis, la bella?, Las señas del esposo, $\bullet$ La difunta pleiteada

Incesto: Delgadina, Silvana, •Amnón y Tamar

Amores desdichados: La aparición de la amada difunta, Alfonso XII, - El quintado, Conde Olinos, $\bullet$ La muerte ocultada, La mala suegra, $\bullet$ Misa de amor, $\bullet$ Conde Alarcos Forzadores y seductores: Blancaflor y Filomena, Rico Franco, El conde preso, $\bullet$ El marinero raptor, La molinera y el cura

Cautivos: La hermana cautiva, El prisionero, Las tres cautivas

\section{RELIGIOSOS}

La buisqueda de la Virgen, El marinero, Santa Catalina, Santa Elena, La Virgen y el ciego, La buenaventura de Cristo, Santa Bárbara, Madre, a la puerta hay un niño, La Virgen romera, $\bullet$ El robo del Sacramento

REFERENTES HISTÓRICOS (pervivencia novelesca)

La muerte de Prim, La muerte del principe don Juan, $\bullet$ El duque de Alba

\section{INFANTILES}

Carabi, Don Gato, Las hijas de Merino, Hilitos de Oro, Mambrú, Las tres cautivas, Monja a la fuerz $a^{39}$

Mercedes Díaz Roig nos presenta en 1990 la siguiente síntesis de la presencia romancística de la tradición americana ${ }^{40}$ :

\begin{tabular}{lcc}
\hline & Romances & Versiones \\
\hline Argentina & 28 & 323 \\
Cuba & 25 & 116 \\
Puerto Rico & 23 & 97 \\
Venezuela & 22 & 171 \\
Dominicana & 21 & 116 \\
Chile & 20 & 137 \\
Colombia & 20 & 197 \\
Uruguay & 19 & 87 \\
México & 16 & 188 \\
Estados Unidos & 13 & 141 \\
Costa Rica & 11 & 54 \\
Nicaragua & 11 & 43 \\
Guatemala & 10 & 26 \\
Perú & 8 & 38 \\
Panamá & 5 & 10 \\
Ecuador & 2 & 2 \\
El Salvador & 1 & 3 \\
\hline
\end{tabular}

Fuente fundamental para el conocimiento del Romancero en América sigue siendo el trabajo bibliográficoi de Merle E. Simmons ${ }^{41}$. El objeto de este amplio, cuidadoso y útil trabajo es, en palabras de su autor, llenar una carencia bibliográfica de México y la mayor parte de Hispanoamérica (exceptúa Chile y Argentina). Simmons pone como límite muy amplio a su recopilación el romance y todas las formas derivadas, no sólo métricamente, de éste. La bibliografía, formada por 2,108 referencias, comprende un apartado general y 19 divisiones que corresponden a los países hispanoamericanos (agrupando Argentina $y$ Uruguay bajo el rubro de Río de la Plata, e incluyendo a Estados Unidos en México). Las referencias cubren una gran cantidad de temas, algunos relacionados sólo en forma muy relativa o lejana con la tradición o la poesía popular, por ejemplo las fichas sobre los sefardíes en la zona del Pacífico de Estados Unidos o sobre autores cultos del siglo XIX. Algunos de los muchos aspectos que cubre este trabajo son la música; fuentes antiguas de textos; obras literarias (novelas, teatro, etc.) y autores cultos que utilizan el romance; reseñas de trabajos; artículos en periódicos; la tradición sefardí; bibliografías; textos diversos que contienen romances o corridos como las crónicas de la Conquista; pliegos sueltos y colecciones de éstos.

\section{TRANSFORMACIONES DEL RO- MANCERO EN AMÉRICA}

Como ha dicho Ana Valenciano, para determinar las variantes más significativas de la tradición del Romancero en América es necesario:

[...] comparar las versiones de cada tema en particular con las del resto de las tradiciones del Romancero pan-hispánico. Pero, antes de enfrentarse con esta labor, conviene separar los textos amañados o de probable origen libresco, y distinguir aquellas actualizaciones, por lo general recientemente importadas, que no han sufrido modificación alguna y por ello no se han incorporado al acervo literario de la tradición autóctona $a^{42}$.

También es conveniente recordar que, a pesar de que muchas veces se ha querido ver en la literatura tradicional y popular «la expresión del alma del pueblo», como ya dijo 
Menéndez Pelayo, no haya nada menos nacional que el folclor. Por otra parte en el ámbito del Romancero la tradición americana no ha sido muy creativa en cuanto a temas, ya que mantiene los comunes, tal vez pudiéramos pensar en creaciones locales en temas como Román Castillo en México. Sin embargo, sí podemos hablar de una unidad de la tradición americana, Carrizo ${ }^{43}$ lo explica recordando la simultaneidad de la Conquista, unidad de religión, lengua, leyes (esto durante el periodo colonial), comercio y difusión de los mismo libros, a lo cual habría que añadir la emigración que también ha mantenido constantes (por ejemplo predominancia de gallegos y asturianos en el siglo XIX).

Los cambios son de muy diverso tipo, los más inmediatos están en la adaptación léxica al contexto, incluyendo topónimos, por ejemplo este final de Delgadina está absolutamente cubanizado, hecho «criollo», con la inclusión de los plátanos maduros:

Angerina se murió en un cuarto muy oscuro y por velas le pusieron cuatro plátanos maduros ${ }^{44}$.

Tenemos versiones mexicanas de este mismo romance que hablan del padre incestuoso como «rey de Morelia», o las versiones de La bastarda que la convierten en «hija del presidente de Chile» en vez de ser sobrina del $\mathrm{Pa}$ pa o el Emperador como sucede en la tradición española.

Esta versión de La mala yerba recogida en Puerto Rico también se ha adaptado al contexto:

- Coja esta criaturita pa el capitán de La Habana; si encontrare a mi padre, por Dios no le diga nada, que éstas son almendras verdes pa el capitán de

$\left[\mathrm{La} \mathrm{Habana}{ }^{45}\right.$.

También hay variación en aspectos más profundos temáticos o estructurales como por ejemplo algunas versiones cubanas, peruanas y colombianas han eliminado el tema del incesto en Delgadina y lo han reemplazado por otros motivos como la desobediencia o el enamoramiento ${ }^{46}$. En versiones sudamericanas de Blancaflor y Filomena la terrible venganza de Blancaflor ha quedado en un simple malparto. En otros casos pueden ser adiciones como el episodio introductorio que justifica la presencia del marido en
Bernal Francés que aparece en versiones mexicanas y centroamericanas, o el duelo final entre el esposo y el amante en versiones del sur de Estados Unidos, Venezuela y Dominicana de La adúltera. También es distinto el final de las versiones estadounidenses y mexicanas de La dama y el pastor ya que estas tradiciones han añadido un episodio en el cual el pastor desdeñoso finalmente requiere de amores a la dama la cual se niega. También es propio de la tradición romancística en América el cruce de Delgadina con Silvana o de El marinero con El barco santo o con Santa Catalina.

Pero las transformaciones también pueden ser de otro tipo y llegar hasta la creación de nuevos géneros como el corrido. En este sentido para Vicente T. Mendoza ${ }^{47}$ la forma de poesía narrativa más difundida en México durante la Colonia fue el romance o corrido andaluz, sobre todo en la región del Centro y en los Estados de Guerrero, Jalisco, México, Michoacán, Oaxaca y Puebla, en los cuales adoptó el nombre de corrido aunque popularmente también suele recibir otros nombres como: romance, tragedia, ejemplo, versos, coplas, «relación». No hay que olvidar que el vocablo corrido se emplea con diferentes acepciones en distintos lugares de habla hispana (al analizar el corrido mexicano generalmente se acepta que el término «es de origen musical y de nacionalidad española», pues en Andalucía se llama así a los romances cantados sin interrupción alguna) como Argentina, Chile, Filipinas y México. El corrido mexicano existe como una forma poética viva, obviamente además de México, en las comunidades hispanohablantes de Estados Unidos (Tejas, California, Nuevo México o Luisiana) o en Centroamérica, especialmente en Guatemala.

En otro lugar he afirmado ${ }^{48}$ el origen hispano del género y señalado que el corrido, como su antecesor el romance, en sus inicios tuvo un marcado carácter épico y «conforme va diluyéndose el espíritu propio de la época revolucionaria» se inclinó a los temas novelescos aunado a ello el influjo del romance vulgar de pliego suelto u hoja volante en el aspecto temático y en algunos elementos formales.

Samuel Armistead ${ }^{49}$ siguiendo el principio de que en cualquier lugar donde se hable español, portugués o catalán se pueden hallar
43

Cf. Juan Alfonso Carrizo, Antecedentes hispano-medievales de la poesía tradicional argentina, Estudios Hispánicos, Buenos Aires, 1945, cap. I.

44

A. Carpentier, op. cit., p. 35.

45

Aurelio M. Espinosa, "Romances de Puerto Ricon, Revue Hispanique, 43 (1918), p. 332-333.

46

Mercedes Díaz Roig, «El romance en América» en Historia de la Literatura Hispanoamericana, Madrid, Cátedra, 1982, t. I, pp. 301-316.

47

Vicente T. Mendoza, El romance español y el corrido mexicano. Estudio comparativo, Universidad Nacional Autónoma de México, México, 1939, pp. 115118.

48

Aurelio González, "¿Cómo vive el corrido mexicano? ¿Quién canta corridos? ¿̇Quiénes cantaron corridos?», Caravelle, 51 (1988), pp. 23-30.

49

Samuel G. Armistead, «Hispanic Traditional Poetry in Lovisiana", en Antonio Sánchez Romeralo, Diego Catalán y Samuel G. Armistead, eds., El Romancero hoy: nuevas fronteras, Segundo Coloquio Internacional sobre el Romancero, Gredos-Seminario Menéndez Pidal, Madrid, 1979, pp. 147-158.

El romancero en América y la tradición cubana

AURELIO GONZÁLEZ 
Américo Paredes, «El concepto de la 'médula emotiva' aplicado al corrido mexicano Benjamín Argumedo", Folklore Americano, XIX/XX-17 (1971-1972), pp. $139-175$

51

Tristam P. Coffin, «Mary Hamilton and the Anglo-American Ballad as an Art Form", Journal of American Folklore, 70 (1957), pp. 208-214.

52

Carolina Poncet y de Cárdenas, «El romance en Cuba», Revista de la Facultad de Letras y Ciencias, 18 (1914), pp. 180-260 y 278-321.

\section{3}

José María Chacón y Calvo, «Romances tradicionales. Contribución al estudio del folklore cubano", Ensayos de literatura cubana, Saturnino Calleja, Madrid, 1922, pp. 83-186. Publicado originalmente en la Revista de la Facultad de Letras y Ciencias, 18 (1914), pp. 45-121. También «Nuevos romances en Cuba», Revista Bimestre Cubana, 9 (1914), pp. 199-210.

\section{4}

Sofía Córdova de Fernández, «El folklore del niño cubano», Revista de la facultad de Letras y Ciencias, 33 (1923), pp. 268306; 34 (1924), pp. 26-52; 35 (1925), pp. $109-156$ y 361418. También publicó materiales en Archivos del Folklore Cubano de 1925 a 1929.

55

William Milwitzky, «El viajero filólogo y la antigua España», Cuba y América, XIX-17 (1905), pp. 307-309 y 325-327.

56

Ana María Arissó, Estudios del folklore sagüero, Instituto de $\mathrm{Se}$ gunda Enseñanza Sagua la Grande, La Habana, 1940.

57

Concepción T. Alzola, Folklore del niño cubano, Universidad Central de Las Villas, Santa Clara, 1961.

58

Nicolás Farray, «Romances y cantares españoles en la tradi-

El romancero en América y la tradición cubana

AURELIO GONZÁLEZ

romances, realizó una investigación en el Estado de Luisiana, Estados Unidos, en dos comunidades hispanas, en las que la mayoría de sus habitantes son pescadores descendientes de emigrantes de las Islas Canarias, entre 1975 y 1976, y recogió varios ejemplos de romances, «décimas», corridos, leyendas, etc. En esa región el género más común de poesía narrativa es el que ellos llaman «décima»: una forma de canción (coplas octosilábicas asonantadas, menos narrativa que el corrido) emparentada con el romance y similar, en estructura y estilo al corrido y que se refiere a los acontecimientos locales, problemas a los que se enfrentan los pescadores, sátiras políticas, historias de animales marinos fantásticos, etc. y considera al corrido, origen de la «décima». Los romances hallados son el reflejo de la supervivencia de la tradición oral hispánica y la existencia de la «décima» demuestra la originalidad y creatividad colectiva y actual en la poesía de tradición oral hispánica a partir del Romancero.

Por su parte Américo Paredes ${ }^{50}$ plantea que una posibilidad de cambio de los textos de tradición oral que se da en la zona americana que él estudia —alejada de la corriente romántica de considerar que el canto folclórico surge en la creación de la danza colectiva y de estimar como más antiguas y valiosas las versiones de cantos (baladas, romances) que en unos pocos versos trazan una situación dramática-, que se apoya en el concepto de «médula emotiva» (emotional core) postulado por Tristram P. Coffin ${ }^{51}$, entre otros, y así, cada balada o romance tiene una médula emotiva esencialmente lírica que prevalece sobre las partes narrativas, en forma tal que a menudo la canción pasa del género narrativo al puramente lírico, tal como sucede con romances y corridos de la región norteamericana fronteriza.

ción cubana», Carlos Magis (ed.), Actas del Tercer Congreso Internacional de Hispanistas, El Colegio de México, México, 1970, pp. 331-344.

59

Mirta Aguirre, "El romance en Cuba y en otros países latino- americanos", Islas, 51 (1975), pp. $217-235$.

60

Susana Redondo de Feldman «Romances viejos en la tradición popular cubana», Revista Hispánica Moderna, 31 (1965), pp. 365-372.

\section{LA TRADICIÓN CUBANA}

En la tradición cubana se encuentran algunos romances considerados como raros en el acervo romancístico americano, entre ellos $\mathrm{La}$ muerte del principe don Juan (pequeño fragmento), El conde Grifos Lombardo, Rico Franco, La mala suegra, Santa Elena, El caballero berido, La muerte de Prim o Silvana (reducido a unos cuantos versos integrados a Delgadina). Aunque este romancero, como en la mayor parte de los países hispanoamericanos, no ha sido suficientemente recogido ni estudiado.

La época de mayor florecimiento de la recolección de romances en Cuba hay que situarla en las primeras dos décadas de este siglo a partir de la publicación del artículo de Carolina Poncet sobre el romance en Cuba ${ }^{52}$ que recogía su trabajo presentado como tesis doctoral un par de años antes. Al trabajo de Poncet siguieron las recolecciones y artículos entusiastas de José María Chacón y Calvo $\left(1914,1922,1925\right.$ y 1926) ${ }^{53}$, Sofía Córdova de Fernández (1925-1929) ${ }^{54}$, con especial atención al romancero infantil, y en menor medida de Carlos A. Castellanos (1920). El primer texto romancístico de la tradición oral moderna cubana fue recogido por William Milwitky ${ }^{55}$ en 1905, después recogieron versiones aisladas José Antonio Fernández de Castro (1923), Emilio Portell Vila Cárdenas (1926), Aurelio M. Espinosa (1930) y Aníbal Otero (1933). En 1940 Ana María Arissó56 recoge textos en Sagua la Grande (en ese entonces provincia de Las Villas), posteriormente Concepción T. Alzola (1954 y 1961) ${ }^{57}$ estudia el folclore infantil y en ese marco recoge versiones de romances. La publicación, póstuma y en forma coleccionada en 1985 a cargo de Mirta Aguirre, de los trabajos de Carolina Poncet $y$, en un apéndice, de los materiales de su archivo personal permitió el acceso a nuevos textos que la investigadora no había dado a conocer en su momento. Por otra parte en distintos artículos se han dado a conocer algunas otras versiones recogidas contemporáneamente por investigadores como, Nicolás Farray $(1967)^{58}$, Mirta Aguirre $(1975)^{59}$ y Susana Redondo de Feldman $(1985)^{60}$, además de las recolecciones, al parecer bastante amplias, hechas para el Atlas de la cultura popular tradicional cubana que se encuentran depositadas y aún inéditas en 
el Centro de Investigaciones «Juan Marine1lo». Casi todos los textos publicados y otros provenientes del Archivo Menéndez Pidal y del archivo de Chacón y Calvo han sido reunidos en el ya citado Romancero general de Cuba preparado en México por Beatriz Mariscal ${ }^{61}$.

Podemos hablar que en la tradición cubana se conocen hasta 40 temas romancísticos, aunque Mercedes Díaz Roig62 los limita a 25 manteniendo algunos que pueden ser discutibles como Mi hijo se ha casado, sin antecedentes peninsulares y que puede ser una canción narrativa como Las bijas de Merino o Carabi

La distribución de versiones por provincias es la siguiente ${ }^{63}$ :

\begin{tabular}{|c|c|}
\hline La Habana & $\begin{array}{l}28 \text { versiones (La Habana 24, } \\
\text { Santa María del Rosario } \\
\text { 3, Marianao 1) }\end{array}$ \\
\hline Santiago de Cuba & 15 versiones \\
\hline Camagüey & 14 versiones \\
\hline Villa Clara & $\begin{array}{l}14 \text { versiones (Sagua la Grande 11, } \\
\text { Santa Clara 2, Regla 1) }\end{array}$ \\
\hline Matanzas & $\begin{array}{l}8 \text { versiones (Matanzas 7, } \\
\text { Cárdenas 1) }\end{array}$ \\
\hline Guantánamo & $\begin{array}{l}5 \text { versiones (Baracoa 1, } \\
\text { Patana Arriba 4) }\end{array}$ \\
\hline Sancti Spiritu & 2 Versiones (Trinidad 2) \\
\hline Cienfuegos & $\begin{array}{l}2 \text { versiones (Cienfuegos } 1 \text {, } \\
\text { Villa Clara } 1 \text { ) }\end{array}$ \\
\hline Oriente ${ }^{64}$ & 1 versión \\
\hline sin lugar & 48 versiones \\
\hline Total & 137 versiones \\
\hline
\end{tabular}

Por los datos que tenemos la dispersión geográfica es amplia y están representadas nueve de las catorce provincias actuales. La parte que aparentemente no está estudiada (cabría la posibilidad, aunque es muy remota, que alguna de las versiones que no indican el lugar fuera de esta región) es la zona occidental, provincia de Pinar del Río. Aunque no aparecen versiones de Las Tunas, Holguín, Ciego de Ávila y Granma la zona sí ha sido tocada. Por otra parte es evidente que las encuestas no han sido sistemáticas salvo la de la tradición sagüera realizada por Arissó en 1940. La abundancia de versiones habaneras se explica casi por una cuestión de simple localización de los investigadores en la capital.

Beatriz Mariscal considera características del romancero cubano el predominio de los temas adaptados a los juegos y corros infantiles y el carácter urbano, así como la presencia lexicalizada de romances eruditos de origen libresco como Roncesvalles (versión recogida en 1928 por Aurelio Espinosa $)^{65}$. Carolina Poncet consideraba que el romance tenía poco auge en Cuba por la predilección popular por la copla lírica, así como por la estrofa más cadenciosa y rica en consonantes de tema amoroso «pueril y quejumbroso» ${ }^{66}$. Los textos recogidos por Farray en el 67 nos muestra que aún en zonas rurales alejadas como la región de Maisí se conserva la tradición del romancero infantil.

Los temas romancísticos que se han recogido en Cuba son los siguientes: El conde Grifos Lombardo (1), Delgadina (9), Silvana (1), La hermana cautiva (3), El conde Niño (Conde Olinos) (7), La malcasada (5), La mala suegra (1), Monja a la fuerza (7), Hilitos de oro (Escogiendo novia) (6), Las hijas de Merino (4), Carabi (5), Mambrú (5), Don Gato (2), Mi bijo se ha casado (1), La dama y el pastor (1), Gerineldo (1)+ La condesita (2), Rico Franco (Isabel) (9), La adúltera (Albaniña) (6), La molinera y el cura (1), Las señas del esposo (12), Madre, Francisco no viene (1), La muerte del principe don Juan (1), Polonia y la muerte del galán (4), Mal de amores (No me entierren en sagrado) (2), Mina el desesperado (7), La aparición (1), Alfonso XII (4), La muerte de Prim (6), Marinero al agua (1), El marinero raptor (1), Roncesvalles (1), Santa Elena (1), Santa Catalina (11) ${ }^{67}$, Santa Bárbara (1), La Virgen romera (1), Madre, a la puerta bay un niño (1), La Virgen y el ciego (1), Por el rastro de la sangre (3), Por aquel postigo, a lo divino, (La Virgen vestida de colorado) (1), ¿Cómo no cantáis la bella?, a lo divino (1).

La presencia del romancero en América ha provocado en distintos países y en distintos momentos diferentes valoraciones o maneras de entenderlo, en ocasiones apasionadas y carentes absolutamente de valor científico, sin embargo, es evidente por estos planteamientos la importancia que tiene en la manera en que se trata de entender la tradición oral, la cultura tradicional y popular para la creación de una identidad nacional, así en México el romance fue núcleo de divergencias en relación con el corrido ya que si bien Vicente T. Mendoza y otros autores señalaban, sin desconocer sus innovaciones y peculiaridades, la clara
61

La autora incluye además los textos recogidos por Carolina Poncet de Dominga Martínez, natural de Entrepeñas, Zamora, y con poquísimo tiempo de residencia en Cuba que publicó como material distinto de la tradición cubana en el «Romancerillo de Entrepeñas y Villar de los Pisones", Révue Hispanique, 57 (1923), pp. 286-314.

62

M. Díaz Roig, Romancero tradicional de América, op. cit., p. 318.

63

A partir de 1976, con la nueva Constitución, Cuba quedó dividida en 14 provincias, que substituyen a las anteriores seis, y por el municipio especial de la isla de la Juventud. Las provincias son: Camagüey, Ciego de Ávila, Cienfuegos, Ciudad de La Habana, Granma, Guantánamo, Holguín, La Habana, Las Tunas, Matanzas, Pinar del Río, Sancti Spiritus, Santiago de Cuba y Villa Clara.

64

La antigua provincia de Oriente hoy en día está dividida en Las Tunas, Holguín, Guantánamo, Granma y Santiago de Cuba. Esta versión fue recogida por Aníbal Otero en El Bollo, Orense, España en 1933 y enviada a Menéndez Pidal.

65

Aurelio M. Espinosa «El tema de Roncesvalles y Bernardo del Carpio en la poesía popular de $\mathrm{Cu}$ ba", Archivos de Folklore Cubano, V-3 (1930), pp. 193-198.

66

Carolina Poncet, «El romance en Cuba», en Investigaciones y apuntes literarios», sel. y pról. Mirta Aguirre, Letras Cubanas, La Habana, 1985, pp. 15-16.

67

Incluyo la versión publicada por Carpentier en La música en Cuba, op. cit., pp. 33-34 no recogida por Beatriz Mariscal en su Romancero general de Cuba.

El romancero en América y la tradición cubana

AURELIO GONZÁLEZ 
Celedonio Serrano Martínez, El corrido mexicano no deriva del romance español, Centro Cultural Guerrerense, México, 1963.

\section{9}

Américo Paredes, «El folklore de los grupos mexicanos en Estados Unidos», Folklore Americano, XIV-14 (1966), pp. 146-163.

\section{0}

Años después será el propio Carpentier quien muestre accidentalmente al recibir en Venezuela unos cuadernos de música que dicha pretendida música precolonial no era más que la música del romance de Don Gato del siglo XVIII.

71

A. Carpentier, La música en Cuba, op. cit., p. 303.

72

Ibid, pp. 32-33.
El romancero en América y la tradición cubana

AURELIO GONZÁLEZ filiación del corrido con respecto al romance hispánico, hubo otros que plantearon desatinos totales como Celedonio Serrano ${ }^{68}$ con su peregrina afirmación nacionalista de que el corrido mexicano no deriva del romance español. Este autor impugna las teorías de Vicente T. Mendoza - y de sus seguidores- sobre el origen hispánico del corrido y defiende apasionadamente el carácter autóctono del género (al cual le señala, más que poco convincentemente, como antecedente directo la antigua poesía náhuatl) sin dejar de reconocer cierta influencia de la poesía tradicional española en la polimetría, el poliestrofismo y la rima varia que caracterizan al corrido. En algún momento esta corriente tuvo seguidores como Mario Colín aunque de forma mucho más matizada.

Con respecto a la tradición hispánica en los Estados Unidos, Américo Paredes ${ }^{69}$ señala que es frecuente referirse al folclor mexicano y al del «México de afuera» (núcleos mexicanos en Estados Unidos) como a dos entidades relacionadas pero distintas, y que entre los folcloristas norteamericanos hay tres grandes corrientes que valoran esas diferencias: la «españolista» (que resalta la «pureza» del folclor méxico-americano), la «difusionista» (que considera al folclor mexicano como la fuente creativa) y la "regionalista» (que concibe al folclor mexicano como "nacional», en tanto que el del «México de afuera» se cataloga como una de tantas regiones folclóricas norteamericanas). Por su parte $\mathrm{Pa}$ redes considera que el choque de pueblos y culturas es el factor principal al cual se deben los rasgos originales del folclor méxico-americano y ejemplifica esta originalidad con el corrido fronterizo (que, según Paredes, surgió antes que el corrido mexicano), canciones satíricas, leyendas, cuentos y juegos infantiles.

En el caso de Cuba el romance también se encontró en medio de diversos planteamientos polémicos sobre la construcción de una identidad nacional. En los años veinte, siguiendo las propuestas de Fernando Ortiz y el grupo del «minorismo», cobra fuerza una línea de reivindicación del elemento negro en la cultura cubana a pesar del rechazo de muchos sectores de la sociedad cubana. Para otros sectores la oposición se da en el sentido que plantean que por nacional se debe entender algo anterior a la conquista española, esto es; el ele- mento indio. Esta posición la encabezan musicólogos como Sánchez de Fuentes, que, sin bases, toman como bandera el Areito de Anacaona ${ }^{70}$.

Sin embargo, la oposición básica se da entre lo «afrocubano» y lo «guajiro»en cuanto a la constitución de una identidad popular. En este sentido Alejo Carpentier dice, a propósito del transmisor guajiro - en contraposición con la creatividad que encuentra en la música mestiza o negra-, que aunque el guajiro es muy poeta:

[...] ciñe su invención poética a un patrón melódico tradicional, que hunde sus raíces en el romance hispánico [...] No crea melodías. En toda la isla, canta sus décimas sobre diez o doce patrones fijos, muy semejantes unos a otros, cuyas fuentes primeras pueden hallarse en cualquier romancero tradicional de Extremadura ${ }^{71}$.

Unos años después, en la década de los cuarenta, el mismo Carpentier reconoce el peso que tiene el elemento hispánico en la conformación de la tradición americana y en este sentido señala el peso que tiene el Romancero y considera que uno de los países de América que mejor han conservado la tradición del romance es Cuba:

El romance heredado, cantado sobre las cunas, transmitido de boca en boca. Muchos conquistadores eran analfabetos. Otros, en cambio, sabían cantar y versar [...] Lo cierto era que, letrados o no, traían toda una tradición poética y musical a bordo de sus carabelas, como lo demuestra la casi increíble propagación de la Delgadina, cuya presencia se ha revelado en los más remotos confines del continente americano [...] con variantes más o menos acentuadas -en las palabras, en la melodía, o en ambas - pero con persistencia de la idea central72.

En la Cuba en el siglo XX, así como González de Eslava en el México del siglo XVI, también encontramos autores cultos que emplean los romances en sus textos, ejemplo de ellos es Alejo Carpentier quien desde luego no se limitó al romance, más bien podríamos decir que éste fue minoritario en relación con las canciones y rituales afrocubanos, los sones y coplas líricas. En Los pasos perdidos (1953) Carpentier retuerce los versos del romance de El caballero burlado de la siguiente forma: 
Soy hijo del rey Mulato

y de la reina Mulatina;

la que conmigo casara

mulata se tornaría ${ }^{73}$.

No hay que olvidar que en su caso el uso de cantos y canciones, "aunque con excepciones, la intención de su presencia y la función que desempeñan es generalmente de crítica, sátira o ataque, y para lograr tales propósitos Carpentier no retrocede ante el anacronismo ${ }^{74}$.

Con respecto a las versiones cubanas del romancero tradicional recogido de la memoria comunitaria cubana en algunos casos éstas se mantienen muy próximas a la tradición peninsular, como en la siguiente versión habanera de Santa Catalina:

En Galicia hay una niña, que Catalina se llama. Todos los días de fiesta, su madre la castigaba porque no quería hacer lo que su padre mandaba y mandó hacer una rueda de cuchillos y navajas, y en medio de la rueda a Catalina arrodillaba. Y bajó un ángel del cielo a salvar a Catalina.

-Sube, sube Catalina, que el Rey de los Cielos te llama ${ }^{75}$.

En muchos casos las versiones de la tradición oral cubana tienen la influencia de la tradición escrita, ya sea la de Flor nueva de Menéndez Pidal o de otros cancioneros y romanceros. En muchos casos se conserva el carácter narrativo, la tendencia al diálogo, y por la influencia musical se da la repetición del último hemistiquio y la inclusión de interjecciones y expresiones como: $A y$, ay, ay o tralá, lalä $\hat{a}^{76}$.

En la tradición cubana encontramos también muchas versiones «vulgata» como las de La bermana cautiva que derivadas de un arreglo moderno en España empiezan con versos similares a «el día de los torneos pasé por la morería». En Cuba estos han variado así:

Señores, voy a contarles la historia de una niñita que cautivaron los moros a los ricos de Melilla.

$$
R G C, 70^{77}
$$

Al salir de Casablanca, cerca de una morería había una mora lavando en una fuente cristalina.

$$
\text { RGC, } 71
$$

Ayer tarde en los torneos pasé por la morería, hallé una mora lavando al pie de una fuente fría. $R G C, 69$
Por el contrario, las versiones del Conde Olinos (Conde Niño) de la tradición de Cuba se apegan a la subtradición extremeña que mantiene la forma de mayor antigüedad.

En otros aspectos sigue los mismo fenómenos que se dan en España y otras regiones de América, así el romance de Gerineldo se encuentra en versiones autónomas y en versiones dobles con el romance de La condesita (que en forma autónoma sólo se ha recogido una versión argentina), aunque según Mercedes Díaz Roig las versiones combinadas de estos dos romances escasean en el panorama americano dos de las tres versiones cubanas continúan con La condesita y la otra cierra la historia con los primeros versos de dicho romance:

Ya se ha formado una guerra entre España y Portugal, y nombran a Gerineldo por capitán general. (RGC, 128)

La tradición cubana también posee textos que no tienen antecedentes peninsulares como el romancillo hexasilábico Mi hijo se ha casado. En esto coincide con otras tradiciones romancísticas hispanoamericanas que han generado textos propios, como la mexicana con Román Castillo.

El motivo viajero «No me entierren en sagrado» aparece en tres textos diferentes, por lo general convertido en elemento nuclear, los temas son: Mina el desesperado, Mal de amores, El caballero herido y Polonia.

En el aspecto léxico el rasgo más característico es la abundancia de diminutivos, por ejemplo, en las versiones cubanas de Delgadina encontramos hijitas, chiquirritica, vasito, padrecito, criadita, casadita, poquita, papaíto, mamaíta, muertecita.

Por otra parte desde el siglo pasado se documentan pervivencias de temas y motivos de romances en distintos tipo de composiciones como por ejemplo «guarachas» que conservan referencias al romance de Don Gato o de Mambrú.

La tradición cubana del Romancero, como la tradición americana en general, vive someti$\mathrm{da}$ a las fuerzas que caracterizan la literatura tradicional, esto es: oscila entre la conservación y la variación. Así por un lado hay versiones que en poco se diferencian de las españolas y en cambio hay otras que siguen nuevos derroteros, pero todas ellas lo que muestran es un
Alejo Carpentier, Los pasos perdidos, en Obras completas, Siglo XXI, México, 1987, t. II, p. 360.

74

Emma Susana Sperati-Piñero, «Cantos y canciones en la obra de Carpentier", Nueva Revista de Filología Hispánica, 35 (1987), p. 529.

\section{5}

Recogida poco antes de 1945 por Alejo Carpentier y publicada en La música en Cuba, op. cit., p. 232.

76

Cf. Tony Évora, Orígenes de la música cubana. Los amores de las cuerdas y el tambor, Alianza, Madrid, 1997, pp. 38-39.

77

Cito siguiendo la edición del Romancero general de Cuba, op. cit. indicando el número de página.

El romancero en América y la tradición cubana

AURELIO GONZÁLEZ 
proceso de adaptación a la realidad americana (en la cual viven como cosa natural, no ajena), realidad a la cual deben su conservación pues, al tratarse de textos de transmisión oral, si la comunidad los ha conservado en su memoria es que de manera propositiva le dicen algo pertinente acerca de su sistema de valores.

Un estudio más profundo del Romancero americano nos permitirá por un lado com- prender mejor otras formas literarias de gran arraigo que se derivan de este género (corridos, décimas, coplas, guarachas), por otra ver los mecanismos de variación y conservación a lo largo de siglos y, finalmente, situar adecuadamente la tradición americana y local de cada país o región en la cultura general del mundo hispánico o ibérico. 